\title{
Characteristics of Headache at Altitude among Trekkers; A comparison between Acute Mountain Sickness and Non- Acute Mountain Sickness Headache
}

\author{
Reza Alizadeh $^{1,2}$, MD; Vahid Ziaee* ${ }^{1}$, MD; Ziba Aghsaeifard ${ }^{1}$, MD; Farzad Mehrabi ${ }^{3}$, MD; Taha Ahmadinejad ${ }^{1}$, MD
}

\section{Authors' Affiliation: \\ 1. Sports Medicine Research Center, Tehran University of Medical Sciences, Tehran, Iran \\ 2. Department of Anesthesiology, AJA University of Medical Sciences, Tehran, Iran \\ 3. Department of Neurology, AJA University of Medical Sciences, Tehran, Iran \\ * Corresponding Authors; \\ Address: Sports Medicine Research, No 7, Al-e-Ahmad Highway, \\ Tehran, Iran \\ E-mail: Ziaee@tums.ac.ir}

Received: Oct 03, 2011

Accepted: Jan 30, 2012

Key Words: High Altitude; Headache; Mountain Sickness; Incidence; AMS

\begin{abstract}
Purpose: Headache at altitudes has had an incidence of $25-62 \%$ through many related studies. Many reasons are identified concerning headache at altitudes such as acute mountain sickness (AMS), sinus headache, migraine, tension type headache, and frontal tension headache. This study tried to compare different types of headache among trekkers on Mount Damavand, a 5671m mountain, Iran, to find their incidence and related symptoms and signs.

Methods: Through a cross-sectional study, we evaluated headache incidence and its correlation to AMS among people who climbed Mount Damavand. Lake Louise Score, a self-report questionnaire, was applied to make AMS diagnosis through three separate stages of trekking programs. Chi-square test was employed as the main mean of analysis.

Results: Totally, 459 between 13-71 year olds participated in the study among which females were $148(32.1 \%)$ and males $311(67.8 \%)$. Headache was found in $398(86.7 \%)$ among whom $279(70 \%)$ were proved as AMS. Investigating the types of headache in the cases of AMS showed $64.5 \%$ to be of steady, $31 \%$ throbbing and $4.5 \%$ stabbing characters which had significant differences with a $P$ value $=0.003$. The majority of headaches were stated as frontal $(38.9 \%)$ and the least prevalence belonged to the parietal area $(4.4 \%)$, while global headache was reported in $27 \%$.

Conclusions: This study specifies the exact location of headaches at altitude in cases of AMS and non-AMS headaches. Many cases of high altitude non-AMS headache are resulted by tension and light reflection at altitude.
\end{abstract}

Asian Journal of Sports Medicine, Volume 3 (Number 2), June 2012, Pages: 126-130

\section{INTRODUCTION}

$\mathrm{H}$ eadache has been considered the most common complaint at altitudes with the incidence of $25 \%$ at less than $2956 \mathrm{~m}$ and $47-62 \%$ at $4928 \mathrm{~m}{ }^{[1-5]}$. High altitude headache (HAH) frequently occurs as an isolated symptom, but in many cases it may be a part of an acute mountain sickness (AMS).

The decrease in partial pressure of oxygen at altitudes reduces the brain supply of $\mathrm{O}_{2}$ and results in increased blood flow in the organ up to $26 \%{ }^{[6]}$ which consequently swells the brain leading to the traction of the meninge and headache due to local traction-irritable mechanoreceptors ${ }^{[7,8]}$. Furthermore, hypoxemia is one of the main causes of releasing inflammatory mediators, causing vasodilatation ${ }^{[9-11]}$.

Acute mountain sickness is an issue described 2000 years ago; first by Tseen Hanshoo through the phrase "Great and Little Headache Mountains" on the trip along the Silk Road ${ }^{[12,13]}$, and later in 403 AD by a monk who addressed the headache as a form of highaltitude sickness ${ }^{[12,14]}$. Up to now, several studies have been conducted focusing on physiological aspects and mechanisms of headache as the major symptom of 
AMS. Nowadays, AMS is defined as altitude-induced headache in addition to at least one typical symptom such as anorexia, nausea, vomiting, insomnia, dizziness and fatigue ${ }^{[1,12,15-17]}$. Altitude above $5500 \mathrm{~m}$ leads to severe hypoxemia, hypocapnia and alkalosis in addition to progressive impairment of physiological function of individuals.

There is also a classification for the sickness by which three types of altitude are categorized according to the specific symptoms. They include high (1500$3500 \mathrm{~m})$, very high $(3500-5500 \mathrm{~m})$ and extreme altitude $(>5500 \mathrm{~m})^{[12]}$.

Headache starts as early as 8-24 hours after arrival at $2000 \mathrm{~m}$ but often is most felt after $48-72$ hours ${ }^{[15]}$.

It should be mentioned that AMS is not the only cause of headache at altitudes. Sinus headache, migraine, Tension-type headache, sunglare and frontal tension headache are the best examples of non-AMSinduced headaches. Through studies on Mount Damavand trekkers, a 5671m mountain near Tehran, AMS had $40-60 \%$ incidence ${ }^{[1,18,19]}$.

This research has been designed to study the whole range of AMS and non-AMS headaches on Mount Damavand.

\section{METHODS AND SUBJECTS}

Through a cross-sectional study, we assessed headache incidence and its correlation to AMS, among people who climbed Mount Damavand. Considering the rate of $38 \%$ of AMS at $4500 \mathrm{~m}$ and over, 362 Participants were included in the study ${ }^{[20]}$.

Lake Louise Score (LLS), a self-report questionnaire [21], was applied to diagnose AMS through three separate stages of ascent. The first stage was at $2900 \mathrm{~m}$ at which the questionnaire was filled by the reviewer after explaining the process in addition to getting verbal informed consents from the trekkers. In this altitude the trekkers' stay time wasn't considerable. AMS was defined as a total score of 3 or more of LLS including headache in addition to at least one of the mentioned symptoms above. HAH was defined as a headache which did not meet the score 3 of LLS ${ }^{[16]}$.
Age less than 13 years, signs or symptoms of acute infection, history of sleeping above $3300 \mathrm{~m}$ and current chronic diseases such as heart and/or renal failure etc were exclusion criteria during the study. Physicians examined the people physically to look for any illnesses or disabilities which were in the exclusion criteria.

The second filling of the LLS was at $4200 \mathrm{~m}$. They stayed in this altitude for minimally 6 hours. Then we assessed any new symptoms or signs after climbing down and reaching the same altitude as a third stage of study. Mental and balance examinations were done through the latter phase in addition to other items. Participants were supposed to reach at least $4200 \mathrm{~m}$ to take part in this stage.

In the case of headache, although no intervention was programmed, people were treated by descending to lower altitude or other suitable measures.

To analyze the data, we used SPSS (version 15), Chi-square test, t-test as the main means of analysis.

\section{RESULTS}

In total, 459 persons between 13-71 years old participated in the study, among whom 333 reached the summit, while 126 (27.5\%) failed to complete the mountain top despite passing the $4200 \mathrm{~m}$ limit. There were 148 (32.1\%) females and 311 (67.8\%) males enrolled in this survey. Most subjects had a range of 2040 years of age (70.1\%). Headache was found in 398 trekkers (86.7\%) among whom $279(70 \%)$ or $61 \%$ of all, were proved as AMS.

Confounding factors such as age, sex, cigarette smoking, oral contraceptive (OCP) usage and other traditional preventive therapies were analyzed to find if they have any correlation with headache. No statistical relationship was observed in this regard.

Investigating the types of headache in the cases of AMS showed $64.5 \%$ to be of steady, $31 \%$ throbbing, and $4.5 \%$ stabbing characters which had significant differences $(\mathrm{P}=0.007)$.

The majority of headaches proved to be frontal (116 cases, 38.9\%) and the least prevalence belonged to parietal area (13 cases, $4.4 \%$ ), while global headache 
Table 1: Association between pain location and AMS-related headache $(\mathrm{P}<0.003)$

$\begin{array}{lccc}\text { Location } & \text { Total number } & \text { As AMS } & \text { As non-AMS } \\ \text { Occipital } & 31 & 31(100 \%) & 0(0.00 \%) \\ \text { Frontal } & 116 & 105(90.5) & 11(9.5 \%) \\ \text { Generalized } & 81 & 71(87.7 \%) & 10(12.3 \%) \\ \text { Parietal } & 13 & 11(84.6) & 2(15.4 \%) \\ \text { Temporal } & 57 & 47(82.5 \%) & 10(17.5 \%)\end{array}$

AMS: acute mountain sickness

was also reported (81 cases, 27.2\%) as figure 1 illustrates. Other locations of headache were parietal (31 cases, 10.4\%) and temporal (57 cases, 19.1\%). Occipital headaches, followed by frontal, were both the most associated with symptoms of AMS comparing to other areas $(P=0.003)$ as observed in table 1 .

One hundred out of 398 cases of headache could not localize the pain and missed the evaluation. Lightheadedness and vertigo were reported by 173 subjects, among which, 128 (74\%) had AMS, while the rate of AMS was $52.8 \%$ among cases without these 2 symptoms.

Out of the 214 who climbed the distance between $4200 \mathrm{~m}$ and $5671 \mathrm{~m}$ (the summit) in less than 6 hours, 126 (58.1\%) got AMS. This was 102 (67.1\%) among the 152 who climbed the distance in more than 6 hours. These rates were not significantly different.

\section{DISCUSSION}

Despite the vast number of trials and performances, there is no exact reason for headache at altitude ${ }^{[22]}$. Lowering the threshold of headache through physical exercises is not a reliable reason per se ${ }^{[22]}$; but, may explain earlier headache occurrence. Low partial $\mathrm{O}_{2}$ pressure $\left(\mathrm{PIO}_{2}\right)$, lessens $\mathrm{O}_{2}$ arterial pressure $\left(\mathrm{PaO}_{2}\right)$ and $\mathrm{CO}_{2} \quad\left(\mathrm{PaCO}_{2}\right)$ through increased ventilation, while arterial oxygen saturation $\left(\mathrm{SaO}_{2}\right)$ stays above $90 \%$ at high altitude ${ }^{[7]}$.

In many circumstances, a cluster headache is induced by altitude which can strengthen the theory of the effect of hypoxemia and hyperventilation on the symptom as the main cause ${ }^{[23,24]}$. This is probably caused by increased blood flow in the brain in response to hypoxia and decrease in $\mathrm{O}_{2}$ at tissue level.

Brain edema is diagnosed clinically by ataxia, loss of consciousness or both in case of AMS or high altitude pulmonary edema (HAPE) ${ }^{[25]}$. HAPE could progress to high altitude cerebral edema (HACE) very fast due to hypoxemia identified by papilledema; retinal bleeding and/or occasional cerebral palsy led by RICP (raised intracranial pressure). Drowsiness followed by stridor is the hallmark of HACE-induced encephalopathy ${ }^{[25]}$. In this study, we did not face any of the above clinical findings.

Hypoxemia seems to start a process of neurohormonal and hemodynamic response, consequently increases micro vascular perfusion and finally results in high hydrostatic pressure in the capillary bed and edema both in lungs and brain. Some authorities propose that the ratio of cerebro-spinal fluid (CSF) to brain volume is closely set with AMS incidence because of CSF shift. The more the ratio, the less the AMS incidence ${ }^{[25]}$.

Biochemical factors (eg, blood brain barrier) changes mediated by vascular endothelial growth factor (GF), bradykinine, and NOS are also considered in the mechanism of AMS ${ }^{[25]}$.

The 70\% AMS rate shows that just less than onethird of the headaches occurring at altitude are not related to the sickness and have other causes. Some causes were mentioned before but one common mechanism may be, contractions in frontal muscles induced by direct sunlight at altitude which irritates the eyes or indirectly through reflection from the snow. This would be studied thoroughly in more trials to compare those who wear glasses and those who don't.

The incidence of headache in our study was $86.7 \%$ and AMS occurred in 70\%. These incidence rates are more than those reported by the others. Jackson et al 
reported 50\% AMS rate during studying 136 trekkers to $4730 \mathrm{~m}^{[16]}$. Kayser et al observed an 84\% AMS incidence through their cohort study on Mount Kilimanjaro in 2008 which exceeds our findings ${ }^{[26]}$, and Karinen identified an incidence of $75 \%$ on Mount Kilimanjaro ${ }^{[27]}$. In another study at $3545 \mathrm{~m}$ on Damavand Mount, prevalence of headache at altitude was $14.3 \%$ while $10.4 \%$ of trekkers had AMS ${ }^{[28]}$.

The most frequent headache in AMS, as seen in some definitions, is the throbbing one ${ }^{[12]}$. In contrast, we found that only $31 \%$ reported a throbbing headache, while $64.5 \%$ experienced a steady one. So, it seems that a throbbing headache is too little related to AMS to include the definition.

Headache is likely to be bi-temporal, frontal or global, more intense during the night and awakening, in common typical forms ${ }^{[12,17]}$. Among AMS cases, $51.5 \%$ suffered from occipital and/or frontal headache. The rate of $82.5 \%$ of temporal pain among AMS cases could strengthen the importance of bi temporal property claimed by some authorities in AMS definition ${ }^{[14]}$. Furthermore, 100\% of the people with occipital headache had the AMS criteria, completely. This shows probable role of increased ICP and brain edema in AMS.

In this study, rapid climbing did not affect headache incidence as great as Jackson et al realized ${ }^{[16]}$. Our most frequent symptoms along with headache were lightheadedness and vertigo; but sleep disturbance was reported as the most common one $(82 \%)$ by Jackson et al ${ }^{[16]}$, and fatigue and sleep disturbance in $64.7 \%$ and $61.8 \%$ trekkers by Halabchi et al $^{[28]}$.

\section{CONCLUSION}

This mild sickness occurs commonly because lots of people often climb rapidly to $2500-3500 \mathrm{~m}$. This study compares the location and type of headaches at altitudes in AMS and non-AMS headaches. The most common involved part of head in altitude was frontal although occipital headache was the most specific for AMS in our study. Almost all the reviews consider high altituderelated low barometric pressure to be responsible for AMS and high-altitude headaches.

\section{ACKNOWLEDGMENTS}

This report is a part of study that has been supported by Sports Medicine Research Center, Tehran University of Medical Sciences Grant (no. 2546). The authors thank Mr. M. Nazarian Afghan (the coach of their university trekking team) for his kind and helpful assistance to the investigators. They are also grateful to the trekkers who participated in this study.

Conflict of interests: None

\section{REFERENCES}

1. Ziaee V, Yunesian M, Ahmadinejad Z, et al. Acute mountain sickness in Iranian trekkers around Mount Damavand (5671m) in Iran. Wild Environ Med 2003;14:214-9.

2. Gertsch JH, Lipman GS, Holck PS, et al. Prospective, Double-Blind, Randomized, Placebo-Controlled Comparison of Acetazolamide Versus Ibuprofen for Prophylaxis Against High Altitude Headache: The Headache Evaluation at Altitude Trial (HEAT). Wild Environl Med 2010; 21:236-43.

3. Basnyat B, Gertsch JH, Holck PS, et al. Acetazolamide $125 \mathrm{mg}$ BD is not significantly different from 375mg BD in the prevention of acute mountain sickness: the prophylactic acetazolamide dosage comparison for efficacy (PACE) trial. High Alt Med Biol. 2006;7:17-27.

4. Basnyat B, Gertsch JH, Johnson EW, et al. Efficacy of low-dose acetazolamide (125 mg BID) for the prophylaxis of acute mountain sickness. High Alt Med Biol 2003;4:45-52.

5. Gertsch JH, Basnyat B, Johnson EW, et al. Randomised, double blind, placebo controlled comparison of ginkgo biloba and acetazolamide for prevention of acute mountain sickness among Himalayan trekkers: the prevention of high altitude illness trial (PHAIT). Br Med J 2004;328:797-9. 
6. Severinghaus JW, Chiodi H, Eger EI, et al. Cerebral blood flow in man at high altitude: Role of cerebrospinal fluid pH in normalization of flow in chronic hypocapnia. Circ Res 1966;19:274 -82.

7. Cymerman A, Rock PB. Medical problems in high mountain environments. A handbook for medical officers. Army Research Inst of Environment Medicine NATICK MA FEB. Report date: Feb 1994. Available at: http://www.usariem.army.mil/pages/download/ highmountain.pdf. Access date: Nov, 2010.

8. Sanchez Del Rio M, Moskowitz M. High altitude headache: lessons from headaches at sea level. Hypoxia: into the next millenium. Adv Exp Med Biol 1999;474:145-53.

9. Strassman AM, Leavy D. Response properties of dural nociceptors in relation to headache. J Neurophysiol 2006;95:1298 -306.

10. Hartmann G, Tschöp M, Fischer R, et al. High altitude increases circulating interleukin-6, interleukin-1 receptor antagonist, and Creactive protein. Cytokine 2000;12:246-52.

11. Maggiorini M, Streit M, Siebenmann C, et al. Dexamethasone decreases systemic inflammatory and stress response and favors vasodilation in high altitude pulmonary edema susceptible at 4559m. Abstract presented at the 16th International Hypoxia Symposium; Chateau Lake Louise, Alberta, Canada; March 10-15, 2009.

12. Paralikar SJ, Paralikar JH. High altitude medicine. Ind J Occup Environ Med 2010;14:6-12.

13. Krieger BP, de la Hoz RE. Altitude-related pulmonary disorders. Crit Care Clin 1999;15:265-80.

14. Rennie D. The great breathlessness mountains. JAMA 1986;256: 81-2.

15. Douglas DJ, Schoene RB. End-Tidal Partial Pressure of Carbon Dioxide and Acute Mountain Sickness in the First 24 Hours Upon Ascent to Cusco Peru (3326 meters). Wild Environ Med 2010;21:109-13.

16. Jackson SJ, Varley J, Sellers C, et al. Incidence and predictors of acute mountain sickness among trekkers on Mount Kilimanjaro. High Alt Med Biol 2010;11:217-22.

17. Silber E, Sonnenberg P, Collier DJ, et al. Clinical features of headache at altitude: a prospective study. Neurology. 2003;60:1167-71.

18. Alizadeh R, Ziaee V, Ghergherchi M, et al. A comparison between incidence of acute mountain sickness in south and north-east pathways of Damavand. J Iran Army Uni Med Sci 2007;5:1189-96. (In Persian)

19. Alizadeh R, Ziaee V, Frooghifard LA, et al. The effect of path and beginning time of ascending on incidence of AMS around Mount Damavand in Iran (5671m). Neurol Res Int 2012 (2012); Article ID 428296.

20. Maggiorini M, Muller A, Hofstetter D, et al. Assessment of acute mountain sickness by different score protocols in the Swiss Alps. Aviat Space Environ Med 1998;69:1186-92.

21. Roach RC, Bartsch P, Hackett PH, Oelz O. Lake Louise. AMS Scoring Committee: the Lake Louise Acute Mountain Sickness Scoring System. In: Sutton JR, Houston CS, Coates G (eds). Hypoxia and Mountain Medicine. Burlington, Vt: Queen City Printers. 1993; Pp:272-4.

22. McCrory P. Headaches and exercise. Sports Med 2000;30:221-9.

23. Kudrow L. The pathogenesis of cluster headache. Cur Opin Neurol 1994;7:278-82.

24. Wayne Massey E. Effort Headache in Runners. Headache 1982;22:99-100.

25. Hackett PH, Roach RC. Current concepts: high altitude illness. N Eng J Med 2001;345:107-14.

26. Kayser B, Hulsebosch R, Bosch F. Low-dose acetylsalicylic acid analog and acetazolamide for prevention of acute mountain sickness. High Alt Med Biol 2008;9:15-23.

27. Karinen H, Peltonen J, Tikkanen H. Prevalence of acute mountain sickness among Finnish trekkers on Mount Kilimanjaro, Tanzania: an observational study. High Alt Med Biol 2008;9:301-6.

28. Halabchi F, Mazaheri R. Acute Mountain Sickness among overnight hotel guests: prevalence, symptoms and signs Tehran Uni Med J 2008;66:560-6. (In Persian) 